\title{
Case Report \\ Our anesthesia experience with a 105 year old geriatric patient
}

\begin{abstract}
In geriatric population ( $>65 \mathrm{age}$ ) higher number of comorbid diseases, increase in the amount of drugs used, physiological changes associated with aging, decrease in organ functions and adaptation problems render geriatric anesthesia more important and special. Therefore, in this case report, our anesthesia experience with a geriatric patient at the age of 105 undergoing operation due to fracture in femur neck is presented.
\end{abstract}

Keywords: Geriatric patients; Anesthetic management; Orthopedics
Volume 2 Issue 3 - 2015

\author{
Ozkan Onal,Aysun Ozdemirkan, Emine \\ Cepni Kutahya, Jale Bengi Celik \\ Department of Anesthesiology and Reanimation, Selcuk \\ University Faculty of Medicine, Turkey
}

Correspondence: Ozkan Onal, Department of Anesthesiology and Reanimation, Selcuk University Faculty of Medicine, Konya, Turkey,Tel +905059052252, Email drozkanonal@selcuk.edu.tr

Received: March 30, 2015 | Published: April 2I, 2015

\section{Introduction}

In association with increased level of development, geriatric population ( $>65$ age) are increasing. Geriatric anesthesia has some special characteristics due to high number of comorbid diseases, high number of drugs used, physiological changes in association with aging, decrease in organ functions and adaptation problems. ${ }^{1}$. The aim of this case report is to share our experiences with a 105 year old geriatric patient undergoing operation in our clinic due to femur neck fracture.

\section{Case}

105year old male patient at the weight of $40 \mathrm{~kg}$ planned for operation due to femur neck fracture was transferred to operating theater without premedication. Electrocardiogram (ECG), pulse oximetry $\left(\mathrm{SpO}_{2}\right)$, invasive arterial blood pressure monitorization for close follow up of hemoglobin and blood pressure was carried out. Bladder catheter was placed for hourly urine monitorization. For probable massive fluid and blood product replacement, peripheric access was made with two $16 \mathrm{G}$ and one $18 \mathrm{G}$ catheters. In preoperative investigation, blood electrolyte level, urea, creatinine levels were normal and $\mathrm{Hb}$ value was $9.9 \mathrm{mg} / \mathrm{dl}$ and as comorbid disease, he had chronic obstructive lung disease. In lung graphy, there was increase in aeration in association with chronic obstructive pulmonary disease (COPD). As medication, he received only ventolin. He had no cardiac complaints and $\mathrm{SpO}_{2}$ value was $87 \%$ and reached $94 \%$ with 5 minutes of pre oxygenation at the rate of $6 \mathrm{l} / \mathrm{min}$. Under sterile conditions, in lateral decubitus position, spinal anesthesia was performed with $12.5 \mathrm{mg}$ izobaric bupivacain (Marcaine, Eczacibasi, Istanbul) patient was taken to supine position and anesthesia level was confirmed with pinprick test and surgical procedure initiated. For normothermia, during surgical procedure, heating was carried out with heating blanket. For perioperative hypotension, $1500 \mathrm{cc}$ crystalloid and 500cc colloid were administered. Hourly urine output was $30 \mathrm{cc}$ and with the administration of $20 \mathrm{mg}$ furosemide, it was increased to $70 \mathrm{cc}$. With serial blood gas analysis, $\mathrm{Hb}$ : value was found to reach 7.5, for which 2 units of erythrocyte suspension were administered. As the need for sedation did not arise, sedative agents were not administered. Following surgical procedure, at control blood gas analysis $\mathrm{Hb}$ was found to be 9.1 and mean arterial blood pressure was within normal range while being followed for some time in recovery unit. Hemodynamy was stable and he was then sent to ward.

\section{Discussion}

In geriatric population, due to physiological, structural and functional changes occurring in organs such as liver, kidney, heart and neurological system, which are important for anesthesia, sensitivity to anesthetic drugs increases and excretion period is prolonged. ${ }^{1,2}$ Decreased hypovolemia compensation in the elderly due to diastolic dysfunction requires careful fluid management in these patients. ${ }^{2}$ Owing to decrease in lung capacity and muscular mass, sensitivity to respiratory depression effects of anesthetics and to the effects of muscular relaxants increases, leading to risk of excessive dose in drugs. ${ }^{2,3}$ Changes in facial structure, difficulties in using mask because of dental problems may increase the risk of difficult airway. ${ }^{2}$ Due to such factors, anesthetists prefer regional anesthesia techniques in lower extremity surgery in geriatric patients. ${ }^{4}$ Similarly, we also found regional technique suitable in our patient. Another advantage of regional anesthesia is that it decreases the risk of bleeding and postoperative embolia in lower extremity surgery with the continuation of postoperative analgesia, sympathetic stimulus may be kept at minimum level or prevent early coronary complications. ${ }^{5}$ However, although they are more advantageous than general anesthesia, in regional techniques, sensitivity to local anesthetics is increased due to decrease in the number of neurons and the amount of neurotransmitters and to decrease in their excretion. ${ }^{2}$ In a previous study, it was established that cardiovascular effects in spinal anesthesia was dependent on anesthesia level rather than local anesthetic substance. ${ }^{6}$ Therefore, for desired level, lower anesthetic doses should be preferred or monitorization of level should be carried out with more frequent intervals. Hemodynamic changes in association with spinal anesthesia may be prevented hence. . $, 7,8$ Another disadvantage of regional technique in geriatric patients is that difficulty and unsuccessful attempts in application owing to degeneration and calcification in vertebrae and impaired spinal anatomy. ${ }^{5}$ In the present case, we did not experience such problems. $12.5 \mathrm{mg}$ bupivacain was administered successfully without addition of opioid with necessary fluid and blood replacement developing in response to surgical bleeding. We determined the level cautiously by using pinprick tests and tried to keep the level at the minimum required for surgery. Decreased urinary clearance in parallel to decreased kidney functions with age was resolved with diuretic agent administration. We took care to prevent hypothermia as it is associated with increased myocardial ischemia in elderly patients. With blood gas 
monitorization, we tried to keep the changes in hemoglobin level at minimum by continuous arterial monitorization. We took into account the increased hemodynamic response to minimum fluid changes in the elderly and carried out fluid replacement in a delicate balance. ${ }^{2}$

\section{Conclusion}

Several case series of anesthesia management in the very elderly patients have been published. Additionally, several factors influence the outcome of the anesthesia and the surgical procedures. These factors also require experienced anesthesiologist and surgeon. In conclusion, in geriatric patients, respiratory difficulty associated with the weakening of muscles, decrease in lung capacity, increased probability of postoperative athelectasia and aspiration due to decrease in reflexes makes general anesthesia risky. ${ }^{9}$ In view of this information and the comparison of advantages and disadvantages of general and regional techniques, and taking probable complications of geriatric population, it is our suggestion that regional techniques are more advantageous and safer than general anesthesia both in perioperative and post-operative period and that they may contribute to a decrease in morbidity and mortality rates.

\section{Acknowledgements}

None.

\section{Conflicts of interest}

The authors declare that there are no conflicts of interest.

\section{Funding}

None.

\section{References}

1. Tüzüner F, Alkış N, Aş̧k İ, et al. Anesthesia in Geriatric Patients, Anestezi Yoğun Bakım Ağrı, MN Medikal \& Nobel, Ankara, Turkey. 2011. p. 43:1088.

2. Kanonidou Z, Karystianou G. Anesthesia for the elderly. Hippokratia. 2007;11(4):175-177.

3. Barash PG, Cullen BF, Stoelting RK. Anesthesia in Geriatric Patients Anestezi, Klinik Anestezi Hand Book. $3^{\text {rd }}$ edn. Turkey: Logos, Istanbul: 1999.p. 445.

4. White PF. Outpatient Anaesthesia. In: Miller RD,Editor. $3^{\text {rd }}$ edn. ewYork, USA: Churchill-Livingstone; 1990. pp. 2025-2059.

5. Gürkan Y. Regional Anesthesia in Geriatric Patients. Turkiye Klinikleri J Anest Reanim-Special Topics. 2011;4(1):44-45.

6. Schnider TW, Mueller Duysing S, et al. Incremental dosing versus single-dose spinal anaesthesia and hemodynamic stability. Anesth Analg. 1993;77(6):1174-1178.

7. Underwood RJ.Experiences with continuous spinal anesthesia in physical status group IV patients. Anesth Analg. 1968;47:18-26.

8. Shroff PK, Skerman JH, Blass NH. Continuous spinal blockade:an old technique revisited. South Med J. 1988;81(2):178-180.

9. Jankovic D. Spinal Anestezi. Regional Bokcs and Infiltration. $3^{\text {rd }}$ edn. Istanbul, Turkey: Logos Yayınc1lik; 2006. p. 272. 